\title{
Genetical and Biochemical Studies of Glucosephosphate Isomerase Deficient Mutants in Saccharomyces cerevisiae
}

\author{
By LUIS S. HERRERA AND CARLOS PASCUAL \\ Department of Microbial Genetics and Biochemistry, \\ National Center of Scientific Research, P.O. Box 6990, Havana, Cuba
}

(Received 14 March 1978)

\begin{abstract}
A number of glucose-negative mutants of Saccharomyces cerevisiae were isolated and shown to contain very low activities of glucosephosphate isomerase. Mutants almost totally lacking this enzyme (less than $1 \%$ of wild-type activity) grew on fructose if provided with a small quantity of glucose. Larger amounts of glucose led to the accumulation of glucose 6-phosphate and growth inhibition. These mutants did not grow on galactose. Other mutants with low enzyme activities (about $1 \%$ of wild type) grew on fructose alone and also on galactose. The mutant characters were determined in both cases by single gene mutations which were mapped on chromosome II and, presumably, identify a structural gene locus for the enzyme.
\end{abstract}

\section{INTRODUCTION}

Glucosephosphate isomerase deficient mutants were first described in Escherichia coli by Fraenkel (1968a) but the lesion had little effect on the physiological behaviour of the cells. Since the hexose monophosphate pathway is indispensable for the synthesis of reduced NADP (Gancedo \& Lagunas, 1973) and glucose 6-phosphate is required for the synthesis of products, such as glycoproteins, glycolipids and constituents of the cell wall, by other pathways, one might expect a profound reduction in glucosephosphate isomerase (EC 5.3.1.9) to be deleterious for normal cell function. However, a glucosephosphate isomerase deficient mutant in yeast, reported by Maitra (1971), did not appear to be affected in this way, and it was able to grow on galactose even though glucosephosphate isomerase catalyses an obligatory step in galactose utilization (Leloir, 1951).

We report here yeast mutants with different deficiencies in glucosephosphate isomerase and examine their effect on the metabolism of various sugars.

\section{METHODS}

Micro-organisms. The following strains of Saccharomyces cerevisiae were used: 196-2 (a hi6); 197-4D ( $\alpha$ hi7), obtained from M. Luzzati, Paris, France; and K1-3D (a ly2-1, me4-1, ty1-1, tr5-18, ac ${ }^{r}$, canl), from the collection of P. P. Puglisi, Parma, Italy.

Media. The complete medium (YP) contained $\left(\mathrm{g}^{-1}\right)$ : yeast extract, 10; peptone, 10. Additional carbon sources (glucose, fructose, galactose or glycerol) were supplied at $20 \mathrm{~g} \mathrm{l}^{-1}$.

The minimal medium was that of Galzy \& Slonimski (1957). In some media, glucose was replaced by fructose. Other additions to the minimal synthetic medium were made according to the nutritional requirements of the strain. For solid medium, Oxoid agar no. 3 was added at $20 \mathrm{~g}^{1^{-1}}$.

Mutagenesis and isolation of glucose-negative mutants. Cells of the haploid wild-type strain 196-2 grown on the $\mathrm{YP} /$ glucose medium were treated with ethyl methanesulphonate as described by Thouvenot \& Bourgeois (1971). The glucose-negative mutants were accumulated and isolated as described by Herrera 
(1976). Glucose-negative mutants were selected for their ability to grow on YP/fructose medium but not on YP/glucose medium.

Yeast growth. The strains were incubated at $30^{\circ} \mathrm{C}$ with shaking at approximately 90 reciprocations min $^{-1}$ and absorbance was read in a Klett-Summerson photocolorimeter.

Genetic analysis. Formation of diploids and their sporulation was examined and tetrad analysis was done as described by Hawthorne \& Mortimer (1960). Complementation tests were performed with diploid cells obtained by the prototroph selection technique of Pomper \& Burkholder (1949).

Assay of enzymes. Activities of glucosephosphate isomerase (EC 5.3.1.9), glucose-6-phosphate dehydrogenase (EC 1.1.1.49) and phosphogluconate dehydrogenase (decarboxylating) (EC 1 1 1. 14) were measured in cell extracts obtained after disrupting the cells in a Braun cell homogenizer model MSK (Bronwill) for $50 \mathrm{~s}$ ( $30 \mathrm{~s}$ first velocity, $20 \mathrm{~s}$ second velocity). During disruption, the flask was cooled with a stream of $\mathrm{CO}_{2}$. The cell extract was immediately centrifuged at $25000 \mathrm{~g}$ for $20 \mathrm{~min}$ at $4{ }^{\circ} \mathrm{C}$, and the supernatant fluid was dialysed against $34 \mathrm{~mm}$-Tris/ $\mathrm{HCl}$ buffer $\left(\mathrm{pH} \mathrm{7.4)}\right.$ at $5{ }^{\circ} \mathrm{C}$ for $18 \mathrm{~h}$. Glucosephosphate isomerase activity was assayed according to Noltmann (1966) in a reaction coupled with glucose-6-phosphate dehydrogenase. Glucose-6-phosphate dehydrogenase was determined according to Kuby \& Noltmann (1966). Phosphogluconate dehydrogenase was assayed according to Pontremoli \& Grazi (1966). Protein was determined by the biuret method (Layne, 1957) using bovine serum albumin as standard.

Intracellular glucose 6-phosphate concentration. After incubation, the culture was immediately cooled to $4{ }^{\circ} \mathrm{C}$ and cells were centrifuged and washed at $4{ }^{\circ} \mathrm{C}$ with an ice-cold solution of sugars at the same concentration as used in the culture medium (to prevent changes in the concentration of metabolites during centrifugation). The flasks were then placed in a dry ice/ethanol bath. Ice-cold perchloric acid was added to yeast cells to a final concentration of $0.7 \mathrm{M}$ and allowed to stand for $30 \mathrm{~min}$. The mixture was centrifuged at $4{ }^{\circ} \mathrm{C}$, the extract was neutralized with $2.5 \mathrm{M}-\mathrm{K}_{2} \mathrm{CO}_{3}$, and protein was precipitated with $\mathrm{ZnSO}_{4}$ and $\mathrm{Ba}(\mathrm{OH})_{2}$. Glucose 6-phosphate was determined in the supernatant by a conventional spectrophotometric assay with glucose-6-phosphate dehydrogenase and NADP (Polakis \& Bartley, 1966). Contamination by glucose was determined by the glucose oxidase-peroxidase method (Bergmeyer \& Bernt, 1963).

Reagents. Glucosephosphate isomerase was obtained from Sigma; glucose-6-phosphate dehydrogenase and fructose 6-phosphate were from Boehringer; glucose 6-phosphate, 6-phosphogluconate and NADP were from Koch-Light; yeast extract and peptone medium were from Oxoid; glucose, galactose, glycerol, amino acids and other nutrients for yeast growth were from BDH; fructose was from Merck.

\section{RESULTS}

\section{Phenotypic characteristics}

A total of 29 mutants were isolated by their failure to grow on glucose either in minimal medium or complex YP medium. All the mutants grew on fructose in complex medium. The mutants were separated into two groups on the basis of their response to fructose in minimal medium and galactose in YP medium: 17 mutants (group 1) grew on these media whereas the other 12 (group 2) did not. The growth of mutant strains representative of both groups and of the wild type is shown in Figs 1 and 2. To establish the nutritional requirements of the group 2 mutants which did not grow on the fructose minimal medium, different nutrients, such as purine and pyrimidine bases and amino acids, were added. None of these supplements, however, had any appreciable effect on growth on the fructose minimal medium.

\section{Genetical and biochemical analysis}

Segregation of the glucose-negative character was studied in three mutants of group 1 $(7 \mathrm{~A}-9,7 \mathrm{~A}-15,7 \mathrm{~A}-24)$ and three of group $2(7 \mathrm{~A}-21,7 \mathrm{~A}-31,7 \mathrm{~A}-32)$. When crossed to wild type each of the six mutants showed monogenic segregation for the glucose-negative character. In the crosses with group 2 mutants, segregants always characteristically showed inability to grow on the three sugars (galactose, fructose and glucose) in the same spore. Recombinants from the six crosses were used for a complementation test with the rest of the mutants. None of the diploids was able to grow on glucose, thus identifying the mutants as defective in the same gene function. All the diploids formed with strains bearing known mutations in the different structural genes of the galactose system (Douglas \& Hawthorne, 1964) were able to grow on YP/galactose medium. 


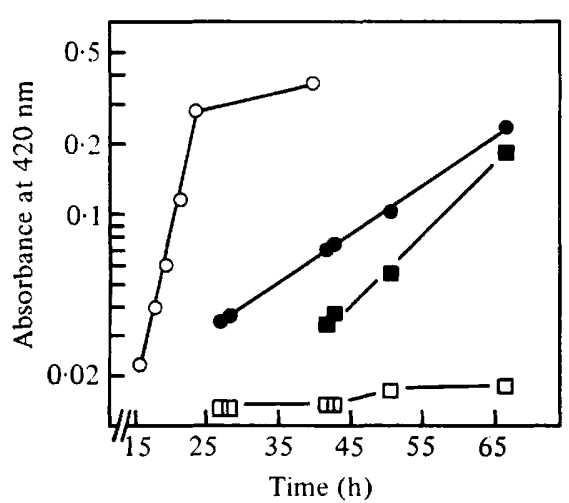

Fig. 1

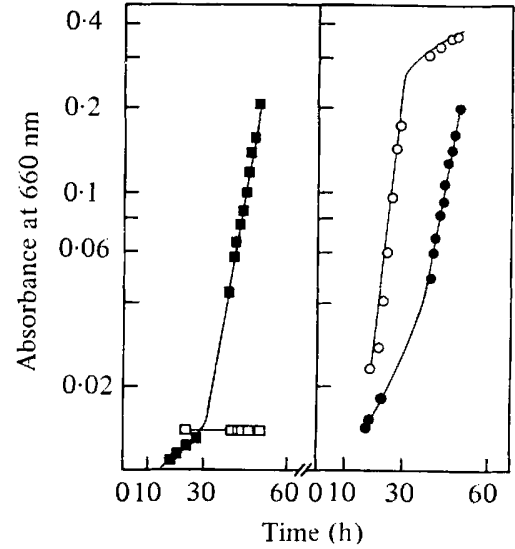

Fig. 2

Fig. 1. Growth of glucose-negative mutants and of the wild-type strain on minimal medium with fructose: $10 \mathrm{ml}$ minimal medium with fructose supplemented with histidine was inoculated at a concentration of $10^{6}$ cells $\mathrm{ml}^{-1}$ for the mutants and $10^{4}$ cells $\mathrm{ml}^{-1}$ for the wild-type strain. Wild type $(\bigcirc, 196-2)$; group $1\left(\square, 7 \mathrm{~A}-9 ; 0,7_{\mathrm{A}-24}\right)$; group 2 ( $\left.\square, 7_{\mathrm{A}-32}\right)$.

Fig. 2. Growth of glucose-negative mutants and of the wild-type strain on YP/galactose medium: $10 \mathrm{ml} \mathrm{YP} /$ galactose medium was inoculated at a concentration of $10^{5}$ cells ml-1 for the mutants and $10^{3}$ cells $\mathrm{ml}^{-1}$ for the wild-type strain. Wild type $(0,196-2)$; group $1\left(\mathbf{\square}, 7_{\mathrm{A}-9} ; 0,7_{\mathrm{A}-24) \text {; }}\right.$ group $2(\square, 7 \mathrm{~A}-32)$.

Table 1 shows the tetrad segregation for the gluc gene with respect to standard genetic markers. As an internal control we checked that segregation of known markers showed the proportions expected according to Mortimer \& Hawthorne (1966). The absence of nonparental ditype asci in $g l u c$ segregation with respect to $t y 1$ place this gene on chromosome II. According to the formula

\section{(3 non-parental ditypes $+\frac{1}{2}$ tetratypes $) \times 100$ total}

the distance from gluc to tyl is 7.8 centi-morgans. Analysis of the segregation patterns for the four loci of chromosome II (gluc, ly $2, t y 1$ and hi7) in individual tetratype asci for gluc and $t y 1$ suggests that the most likely sequence is $l y 2-t y 1-g l u c-h i 7$.

Table 2 shows the specific enzyme activities in three group 1 mutants, in two group 2 mutants and in the wild-type strain 196-2. All the mutants had a marked deficiency in glucosephosphate isomerase activity: those in group 1 had about $1 \%$ of the wild-type activity and those in group 2 about $0.25 \%$ of the wild-type activity.

On the basis of these results, we propose the hypothesis that the group 2 mutants are unable to grow on the fructose minimal medium because their content of glucosephosphate isomerase is too low to permit a sufficient steady-state level of glucose 6-phosphate for the requirements of the hexose monophosphate pathway or biosynthetic pathways. If this hypothesis were correct, addition of a small quantity of glucose to the fructose minimal medium should restore growth of the mutants. Growth of mutant $7 \mathrm{~A}-32$ did, indeed, show a dependence on the glucose concentration in the medium (Fig. 3). This dependence was less for mutant $7 \mathrm{~A}-24$, and practically absent for the wild-type strain. External glucose concentrations higher than $0.4 \mathrm{mg} \mathrm{ml}^{-1}$ inhibited the growth of both mutants (Fig. 3). 
Table 1. Tetrad analysis of data from crosses involving the glucl gene and other markers Numbers of tetrads [parental (PD) and non-parental (NPD) ditypes and tetratypes $(T)]$ are shown as $\frac{P D: N P D}{T}$.

$\begin{array}{lclcccc} & \text { tr5 } & \text { me4 } & l y 2 & t y 1 & \alpha & \text { hi7 } \\ \text { glucl } & \frac{4: 6}{41} & \frac{6: 6}{40} & \frac{17: 1}{34} & \frac{43: 0}{8} & \frac{10: 7}{34} & \frac{31: 5}{55} \\ \text { tr5 } & & \frac{6: 10}{37} & \frac{10: 6}{35} & \frac{4: 3}{36} & \frac{11: 20}{22} & \frac{3: 6}{12} \\ \text { me4 } & & & \frac{9: 11}{35} & \frac{7: 3}{44} & \frac{7: 8}{40} & \frac{3: 2}{17} \\ l y 2 & & & \frac{19: 1}{32} & \frac{13: 7}{36} & \frac{3: 1}{18} \\ t y 1 & & & & \frac{10: 8}{34} & \frac{10: 1}{11} \\ \alpha & & & & & \frac{12: 18}{60}\end{array}$

Table 2. Glucosephosphate isomerase (GPI), glucose-6-phosphate dehydrogenase (G6PD) and 6-phosphogluconate dehydrogenase (6PGD) activities of the wild type and mutant strains

Cells were grown aerobically at $30^{\circ} \mathrm{C}$ in fructose medium and collected at the end of the exponential phase. Specific activities are expressed as $\mu \mathrm{mol} \mathrm{min}^{-1}(\mathrm{mg} \text { protein })^{-1}$.

\begin{tabular}{lccc} 
& \multicolumn{3}{c}{ Specific enzyme activity } \\
Strain & $\overbrace{\text { GPI }}$ & G6PD & 6PGD \\
196-2 (wild type) & 1500 & 185 & 65 \\
Group 1 mutants & & & \\
7A-24 & 10 & & \\
& $20 \cdot 6$ & 178 & 45 \\
7A-9 & $17 \cdot 0$ & 114 & \\
7A-15 & $11 \cdot 2$ & 142 & 45 \\
Group 2 mutants & $17 \cdot 0$ & 134 & \\
7A-31 & $3 \cdot 0$ & 146 & 39 \\
7A-32 & $2 \cdot 6$ & 198 & 54 \\
& $2 \cdot 7$ & 178 & 42 \\
& $3 \cdot 4$ & &
\end{tabular}

Figure 4 shows the intracellular concentration of glucose 6-phosphate after incubation in fructose minimal medium plus different concentrations of glucose. The intracellular concentration of the phosphorylated sugar in mutant $7 \mathrm{~A}-32$ had a marked dependence on the external glucose concentration. This dependence was less for mutant $7 \mathrm{~A}-24$, and absent for the wild-type strain.

The yeast extract employed in the YP media was subsequently found to contain $0.4 \%$ (w/v) glucose. This might explain why the group 2 mutants grew on YP/fructose medium without addition of glucose. At any rate, best growth in the YP/fructose medium was obtained when glucose was added at $0.05 \mathrm{mg} \mathrm{ml}^{-1}$.

\section{DISCUSSION}

Genetic analysis of the mutants showed that the lesions present in all of them were monogenic for the glucose-negative character. Therefore, the pleiotropic effect found in mutants of group 2 could be related to the low activity of glucosephosphate isomerase. 


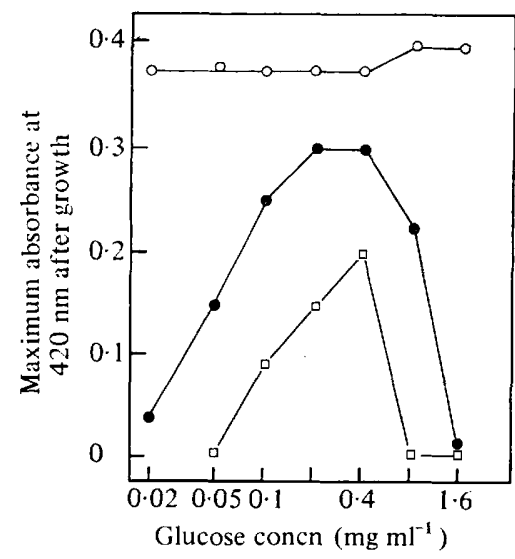

Fig. 3

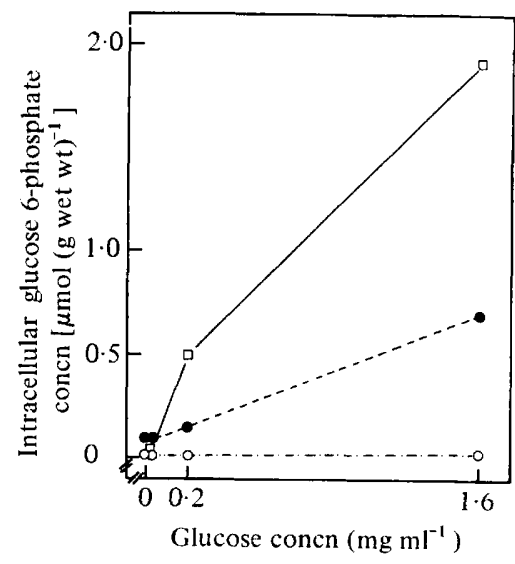

Fig. 4

Fig. 3. Growth on fructose minimal medium with histidine and glucose: $10 \mathrm{ml} 2 \%$ fructose minimal medium supplemented with histidine and different concentrations of glucose was inoculated at a concentration of $10^{4}$ cells $\mathrm{ml}^{-1}$. The incubation was stopped when no further increase in absorbance was observed. Wild type $(O, 196-2)$; group $1\left(0,7_{A}-24\right)$; group $2\left(\square, 7_{A}-32\right)$.

Fig. 4. Effect of glucose on the intracellular concentration of glucose 6-phosphate. Strains were inoculated into minimal medium supplemented with histidine, $2 \%$ fructose and different concentrations of glucose. The inoculum level was adjusted according to the growth rate for each strain in the different media employed so that the final concentrations of cells were similar for all cultures after $24 \mathrm{~h}$ incubation. At the end of this period, the cells were harvested and washed by centrifugation in the cold, and then the intracellular concentration of glucose 6-phosphate was determined. Wild type $(\bigcirc, 196-2)$; group $1\left(\odot, 7_{A}-24\right)$; group $2(\square, 7 \mathrm{~A}-32)$.

According to Lagunas \& Gancedo (1973), Saccharomyces cerevisiae requires $8.7 \mu \mathrm{mol}$ NADPH (mg cell dry wt $)^{-1}$ to be synthesized by the hexose monophosphate pathway. Hence a yeast cell with a doubling time of about $150 \mathrm{~min}$ would require an isomerase activity of about $60 \mu \mathrm{mol}$ (g protein) ${ }^{-1} \mathrm{~min}^{-1}$ for converting fructose 6-phosphate to glucose 6-phosphate. This analysis permits one to explain why mutants of group 2 did not grow on the minimal fructose medium since their residual glucosephosphate isomerase activity would place their doubling time at more than $50 \mathrm{~h}$. Mutants such as $7 \mathrm{~A}-24$, with a residual activity of about $15 \mu \mathrm{mol}$ (g protein) $)^{-1}$ min $^{-1}$, had a doubling time of about $13 \mathrm{~h}$, in good agreement with the predicted behaviour. The above considerations indicate that a sufficient steady-state level of glucose 6-phosphate is important for cell growth as seen in the experiment where glucose was added to a concentration of less than $0.4 \mathrm{mg} \mathrm{ml}^{-1}$ to the minimal fructose medium. The intracellular concentration of glucose 6-phosphate seems to be regulated fundamentally by the activity of glucosephosphate isomerase.

The observed growth inhibition by glucose in the mutants $(7 \mathrm{~A}-24,7 \mathrm{~A}-32)$ is probably related to the toxic effect of glucose 6-phosphate (Maitra, 1971; Fraenkel, 1968b). Growth inhibition caused by a reduced uptake of fructose by glucose competition seems an unlikely explanation, since the ratios of fructose/glucose concentration used in the present experiments are far from the values required to cause an exclusion of fructose by glucose either at the level of transport (Kotyk, 1967; Cirillo, 1968) or of phosphorylation (Dixon \& Webb, 1964).

Glucosephosphate isomerase activity is necessary for galactose utilization (Leloir, 1951). Therefore, the inability of group 2 mutants to grow in the YP/galactose medium was 
expected, since the residual glucosephosphate isomerase activities in these mutants are not sufficient to meet the requirements of the glycolytic pathway.

The glucosephosphate isomerase deficient mutants isolated by Maitra (1971) probably resemble our group 2 mutants since they were selected as colonies that grew on a fructose minimal medium but not on glucose.

Our results demonstrate that the almost total absence of glucosephosphate isomerase has a drastic effect on the normal cell function in $S$. cerevisiae, in contrast to Escherichia coli (Fraenkel, 1968a; Fraenkel \& Levisohn, 1967) where the loss of this enzyme seems to have very little effect on the physiological behaviour.

The authors are very grateful to Dr Amati and Dr Kotyk for critical reading of the manuscript and personal encouragement. They wish to thank Dr P. P. Puglisi for providing the strains. The technical assistance of María D. Noa is gratefully acknowledged.

\section{REFERENCES}

Bergmeyer, H.-U. \& BernT, E. (1963). D-Glucose determination with glucose oxidase and peroxidase. In Methods of Enzymatic Analysis, pp. 123130. Edited by H. U. Bergmeyer. New York and London: Academic Press.

CIRILLo, V.P. (1968). Relationship between sugar structure and competition for sugar transport system in baker's yeast. Journal of Bacteriology 95, 603-611.

Dixon, M. \& WeBb, E. C. (1964). Phosphotransferases. In Enzymes, pp. 215-218. Edited by M. Dixon and E. C. Webb. London: Longmans Green.

Douglas, H. C. \& Hawthorne, D. C. (1964). Enzymatic expression and genetic linkage of genes controlling galactose utilization in Saccharomyces. Genetics 49, 837-844.

Fraenkel, D. G. (1968a). The accumulation of glucose-6-phosphate and its effect in an Escherichia coli mutant lacking phosphoglucose isomerase and glucose-6-phosphate dehydrogenase. Journal of Biological Chemistry 243, 6451-6457.

FraENKel, D. G. $(1968 \mathrm{~b})$. Selection of Escherichia coli mutants lacking glucose-6-phosphate dehydrogenase or gluconate 6-phosphate dehydrogenase. Journal of Bacteriology 98, 1267-1271.

FraENKEL, D. G. \& LeVISOHN, S. R. (1967). Glucose and gluconate metabolism in Escherichia coli: a study of a mutant lacking phosphoglucose isomerase. Journal of Bacteriology 93, 1571-1578.

Galzy, P. \& Slonimski, P. P. (1957). Variations physiologiques de la levure au cours de la croissance sur l'acide lactique ou sur le glucose comme seule source de carbone. Comptes rendus hebdomadaire des séances de l'Académie des sciences 245, 2423.

Gancedo, J. M. \& Lagunas, R. (1973). Contribution of the pentose phosphate pathway to glucose metabolism in $S$. cerevisiae: a critical analysis of the use of labelled glucose. Plant Science Letters 1, 193-200.

Hawthorne, D. C. \& Mortimer, R. K. (1960). Chromosome mapping in Saccharomyces: centromere-linked genes. Genetics 45, 1085-1110.
Herrera, L. (1976). Use of snail enzyme for the selection of glucose and mannose negative mutants in Saccharomyces cerevisiae. Mutation Research 34, 123-130.

KoTYK, A. (1967). Properties of the sugar carrier in baker's yeast. II. Specificity of transport. Folia microbiologica 12, 121-131.

KubY, S. A. \& Noltmann, E. A. (1966). Glucose6-phosphate dehydrogenase (crystalline) from Brewer's yeast. Methods in Enzymology 9, 116-125.

LAGưnas, R. \& Gancedo, M. (1973). Reduced pyridine nucleotide balance in glucose-growing S. cerevisiae. European Journal of Biochemistry 37, 90-94.

LAYNE, E. (1957). Spectrophotometric methods and turbidimetric methods for measuring proteins. Methods in Enzymology 3, 447-454.

LELOIR, L. F. (1951). The enzymatic transformation of uridine diphosphate glucose into a galactose derivative. Archives of Biochemistry 33, 186-190.

MatTRA, P. K. (1971). Glucose and fructose metabolism in a phosphoglucose isomerase less mutant of Saccharomyces cerevisiae. Journal of Bacterio$\log y$ 107, 759-769.

Mortimer, R. K. \& Hawthorne, D. C. (1966). Genetic mapping in Saccharomyces. Genetics 53, 165-173.

Noltmann, E. A. (1966). Phosphoglucose isomerase. Methods in Enzymology 9, 557-565.

Polakis, E. S. \& Bartley, W. (1966). Changes in the intracellular concentrations of adenosine phosphate and nicotinamide nucleotides during the aerobic growth cycle of yeast on different carbon sources. Biochemical Journal 99, 521-533.

PoMPer, S. \& Burkholder, P. R. (1949). Studies on the biochemical genetics of yeasts. Proceedings of the National Academy of Sciences of the United States of America 35, 456-464.

Pontremol, A. \& GrazI, E. (1966). 6-Phosphogluconate dehydrogenase (crystalline). Methods in Enzymology 9, 137-141.

Thouvenot, D. R. \& Bourgeors, C. M. (1971). Optimisation de la sélection de mutants de Saccharomyces cerevisiae par la nystatine. Annales de l'Institut Pasteur 120, 617-625. 